\title{
Verification of Strategic Management Process Model in SME into Practice
}

\author{
Veronika SVATOŠOVÁ \\ Mendel University in Brno, Brno, Czech Republic \\ veronika.svatosova@mendelu.cz
}

\begin{abstract}
Implementing the principles of strategic management into business processes improve decision-making, reduce cost, increase productivity and overall performance of business. Nevertheless, this area is in practice deeply underestimated, especially in small and medium-sized entrepreneurship, in which strategic management is often confused with operational and tactical management. The main goal of paper is to verify the validity of strategic management process model in small and medium-sized entrepreneurship into practice. The model derives from previous research activities that identify strengths and weaknesses in strategic management process of SMEs and optimizes the whole process. The model is simulated on the example of selected SME based on restrictive criteria. The main research methods used in this paper are case study, personal interviewing, financial analyzing, modelling and simulating. The simulation of proposed model into practice verified its validity into practice and showed that its implementing into business could optimize and improve the whole processes and explored the area in small and medium-sized entrepreneurship.
\end{abstract}

Keywords: Strategic Management, Simulation, Modelling, Case Atudy, Small and Medium-sized Entrepreneurship.

\section{Introduction}

Implementing the principles of strategic management is considered to be a decisive factor in long-term business success. It helps to long-term strategic development, improve overall effectiveness, productivity, cost efficiency, and other related to them. Despite of the importance of strategic management for strategic business development, this area is in practice is deeply underestimated and is often confused with operational and tactical management, especially in the area of small and medium-sized entrepreneurship. These findings may cause an impossibility to be in long-term developed. Srpová, Řehoř et al. [10] also highlight that in small-sized enterprises, operational management usually prevails over the strategic one, while oral communication prevails over the written one. Work is distributed among staff somewhat spontaneously; any decision is normally based on the current mood of the entrepreneur or manager. North and Varvakis [8] stated the manifold effect of low productivity among SMEs that makes it impossible for them to expand. Low 
productivity does not only lead to loss of the home market due to foreign competitiveness but also reduces the possibilities of integration in international value chains. The resulting fragility of SMEs reduces their innovation capabilities and options for upgrading production, which again results in low productivity. According to Durgulu et al. [4], SMEs are increasingly compelled to develop strategies to increase their effectiveness and sustainability, in order to gain financial and performance goals. According to Šebestová and Nowáková [9], we can distinguish companies (including both SMEs and big firms) in terms of business strategy development into three categories: (1) Companies that have a well-planned and detailed written primary strategic document (business plan); (2) Companies that have a strategic document drawn up in some written but concise form, with insufficient details in all important chapters; (3) Companies that have no written strategic document; it is never clear if the strategy is kept in the mind of top management, some parts are the subject of company culture or do not exist at all. According to research [6], the majority of examined Czech small and medium-sized enterprises (60\%) had a formulated strategy. Otherwise, the research of author [13] focused on importance of strategy and strategic management for SME found out only $47 \%$ of SMEs formulated any strategy of which only $27.5 \%$ formulated the strategy in written form. Based on identified strengths and weaknesses of SMEs in process of strategic management, the process model of strategic management in SME optimizing the whole process has been proposed. The main purpose of this paper is to verify a validation of this proposed process model in practice by simulating on an example of selected enterprise fulfilling set criteria.

\section{Theoretical Framework}

According to Zich [16], strategic continuity of level of goals has several important aspects. First and foremost, goals must be clearly stated to be achieved. Defining goals must be based on the overall imagination of the development of company. It could be generally considered that there is a link to the vision and mission, which would, however, in most cases mean the owner's point of view. The requirement for development should also take into account the element of the time frame. Although it is already contained in each essence of management, in the context of the strategy, it nonetheless requires special attention. This stems from the fact that the goals, which will be the main elements of the strategy, should cover all key activities and all levels of the company.

Strategy in SME is defined as a set of [2]: planned activities being carried out to achieve stated objectives, resources and capabilities being deployed to action strategic decisions, market being entered, explored and learned from, competitor being engaged and benchmarked, environments providing signals filtered through personal and entrepreneurial networks. Critical factors in SME strategies in the form of a model are the following [11]: Entrepreneurial management behaviour - opportunity identification, resource leveraging, networking, effectual decision-making, creativity and innovation; Knowledge/technical skills - product/service knowledge, 
market/industry understanding, IP knowledge; Personal attributes - innovative, determined, external focus, team leader; Strategic management competencies marketing, finance, human relations; Critical internal factors - motivations; Critical external factors - market sector, barriers to entry, adjustments.

Strategic management can be defined as an art and science formulating, implementing and evaluating cross-functional decisions that enable an organization to achieve its objectives. It has been discussed that the dominant paradigm in strategic management is a model characterized by two functions: strategy formulation and implementation [7, 1]. Strategic management consists of research, review, assessment and selection efforts required for planning strategies; putting into action any kind of precautions within the organization in order for these strategies to be implemented and all activities related with controlling the works performed [5]. There are many benefits in adapting strategic management in SME [3, 1]: it helps strategists to understand the current situation of the enterprise and have a clear sense of vision and mission; it enables managers to assess the strengths and weaknesses and focus on what is strategically important; it helps to establish proper goals and prepare the means to achieve them; it allows an enterprise to be more proactive than reactive and to be ready to face any controlled and uncontrolled issues and situations. Some SMEs still avoid using strategic management. The reasons are the following [3, 1]: lack of knowledge of strategic management techniques, lack of time and/or inability to plan; SME managers may be unaware of the importance of strategic management for their business; the lack of information and knowledge about strategic planning and its advantages will lead to an inability to establish a strategic management system within their enterprises; lack of attention paid to financial indicators such as cash flow; lack of necessary managerial skills; excessive involvement in daily and routine operations; anxiety about the uncertain future; low number of employees or poor management information system, i.e. ineffective data recording systems.

\section{$3 \quad$ Materials and Methods}

The purpose of this paper is to verify the proposed process model of strategic management in small and medium-sized entrepreneurship into practice with a help pf model simulation on the example of selected enterprise. This model derives from the previous research activities exploring the quality and importance of strategic management for strategic development among selected research sample of SMEs [12, 14]. This research also identified the determinants of strategic development [12]. These determinants are distinguished into three main categories: general aspects of strategic management (mission and vision, situational analysis, corporate strategy formulation, strategy implementation, strategy control), internal factors of strategic development (corporate culture, quality of management, marketing strategy and management, financial strategy and management, human resources strategy and management, production strategy and production policy, competitive advantage, flexibility, innovation ability, financial condition) and external factors of strategic development (orientation in industry, ability to work with legislation, negotiation 
with customers, negotiation with suppliers, struggle with competition). Focusing on these determinants could support more effective application of strategic management in SME and further strategic development of SME. Based on determinants for strategic development in SME, the process model of strategic development in SME has been proposed and after that verified and simulated in practice $[12,14]$.

The main aim of this process model of strategic management in SME is to identify the strengths and weaknesses identified in strategic management process in small and medium-sized entrepreneurship that optimizes the whole process and support strategic and competitive position of SME on the market. The main research methods are the analysis of internal documents, the method of personal interviewing, case study and modelling and simulating. The case study points out the main strengths and weaknesses of the enterprises in strategic management and other aspects of strategic development. Based on the findings of case study, the determinants of optimal strategic development have been demonstrated in practice. Simultaneously, the main benefits and shortcomings in process of strategic management have been identified The main purpose of this simulated model is to prevent from the most common shortcomings in strategic development and provide a recipe and recommendations for the long-term business success for the selected company and other SMEs.

Simulation of this model is realized in the form of case study, for which the selected enterprise fulfilling the following criteria has been analysed: enterprises belonging to SMEs (i.e. enterprises with 1 to 249 employees), scope of business: according to CZ-NACE Section F (Building industry), headquarters: in the Czech Republic in South Moravian Region, legal form of enterprise: joint-stock company. This enterprise is indicated as enterprise A under the promise of its anonymity. The criteria for the selection of this enterprise are the same as in the previous research [13].

\section{$4 \quad$ Results and Discussion}

This chapter is divided into two main parts - description of process model in SME as a result of previous research activities $[12,14]$ and the further simulation of this model on the selected agricultural company. This model verifies its practical application and functionality and highlights the main benefits and shortcomings in the process of creating and implementing the strategy of selected enterprises. The process strategy model simulation compares theoretical knowledge about processing of strategy and strategic management in SME, theoretical identification of determinants of strategic development in SME and practical usage and its functionality in business practice (mainly using the experience and opinions of owner-managers of SME).

\subsection{Proposal of Process Model of Strategic Management in SME}

The previous research activities helped to propose process model of strategic development in SME respecting identified determinants for strategic development 
[12]. This model (see figure 1) is consequently specialized and adopted to the results of research realized among representative research sample of SME [15].

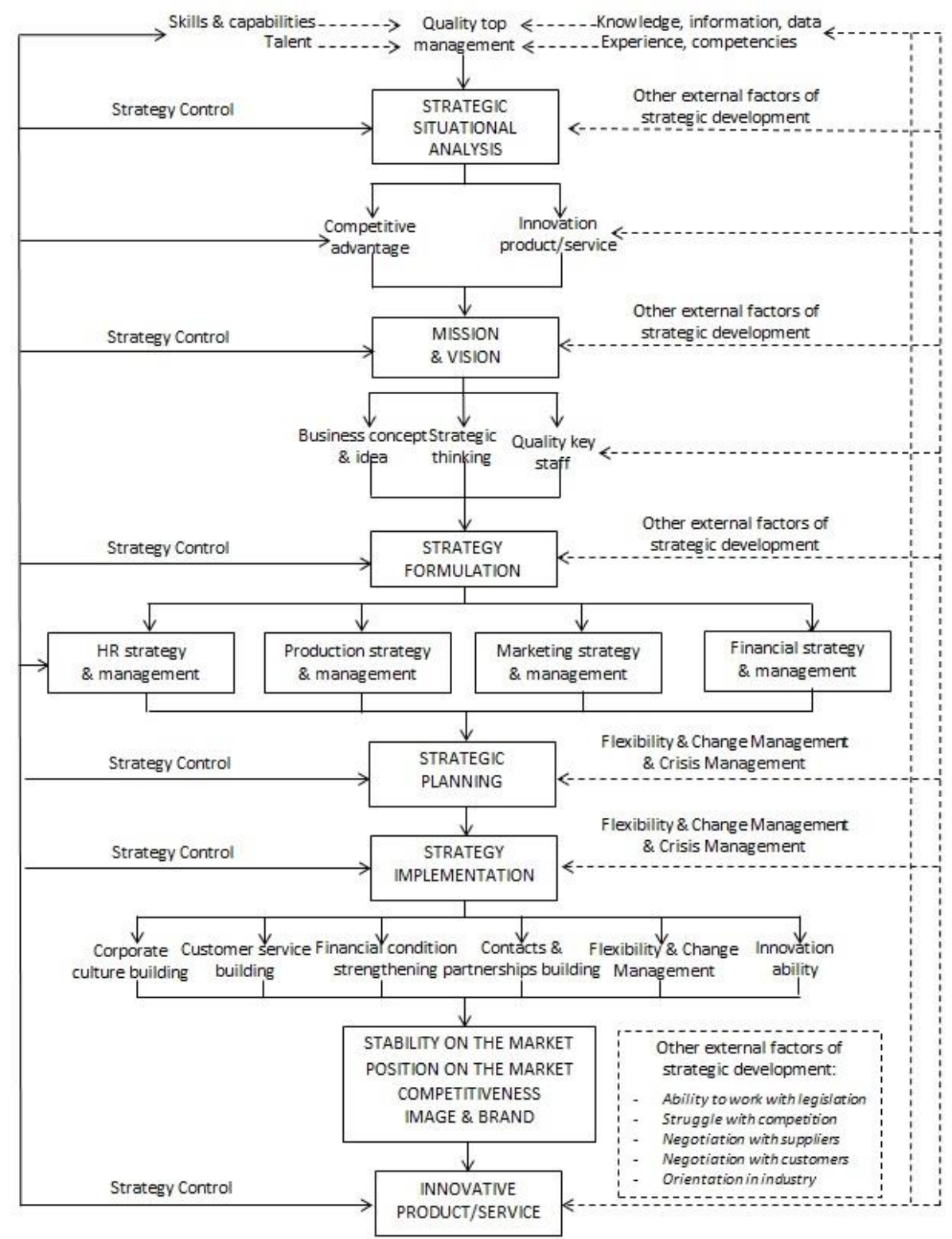

Fig. 1. Process Model of Strategic Management in SME [15].

This model identifies problematic areas (weaknesses) and highlights strong areas (strengths) to prevent from threats and to use future opportunities for other strategic 
development. The main shortcomings of SMEs in strategic management process are based on the matter of fact only minority of them formulated any corporate strategy and functional strategies are underestimated and determinants and key elements of strategic development are not considered as equally important. Situational analysis is not considered as important including defining mission and vision, strategy control is underestimated as well. Flexibility, change management and crisis management practically do not exist in strategic management process among selected SMEs. External factors of strategic development are not taken account for other strategic decision-makings, especially orientation in industry and negotiation with customers. We can conclude in practice SMEs do not use comprehensive insight on implementing principles of strategic management and practically no strategic approach to the strategic management process is implemented. The findings might be a reason for impossibility of strategic development in SME. On the other hand, the SMEs are aware of importance of strategy formulation and implementation together with strategic thinking and strategic planning. The other determinants, such as quality of management, corporate culture, financial condition, competitive advantage and innovation ability, are considered as very important for other strategic development. Despite of this fact, SMEs do not know how to optimize the whole process of strategic management for other strategic development. The possible solution could be a proposed process model of strategic management in SME that is described as following. The main path respects the basic steps of strategic management, i.e. strategic situational analysis, strategy formulation, strategic planning and implementing and strategy control. This main path is in figure 1 framed (the main line of the whole process). The prerequisite of the whole process is quality skills, knowledge and experience of top management enabling to precise this process. The process then continues with situational analysis exploring internal and external factors influencing the enterprise. It is then important to define competitive advantage and unique innovation product/service that is considered as the important determinant for strategic development in SME. Based on results of situational analysis, the mission and vision is formulated as a prerequisite of main basic business concept and idea, strategic thinking and finding and keeping key staff. After that, the main corporate strategy is formulated, from which functional strategies are with the same priority identified, i.e. HR strategy, marketing strategy, financial strategy, production strategy with further proposal of their effective management. The process is then followed by proper strategic planning and plan. Corporate and functional strategies are then implemented with respecting and implementing corporate culture building, customer service building, caring of financial condition, searching strategic contacts and partnerships including respecting main principle of change and crisis management, i.e. to be as flexible as possible. When the previous steps of that process is respected, there is a high probability of reaching main business goals, i.e. required position and stability on the market, competitiveness, image building and brand building that support further strategic development. These goals lead to other innovation of core unique product/service strengthening the other competitive position on the market. The whole process is followed by strategic controlling and involving positive and negative aspects of other external factors of strategic development (orientation in 
industry, negotiation with customers, negotiation with suppliers, ability to work with legislation, struggle with competition). This model respects the previous one (figure 1) implementing main path and principles of strategic management process. The main benefits of this model are based on optimizing the whole strategic management process involving all main key elements and determinants for strategic development, highlighting main strengths and eliminating main weaknesses realized in practice by SME. The other benefit of this model is not only based on optimizing the whole process but also based on supporting the long-term strategic development in SME. [15]

\subsection{Simulation of Process Model of Strategic Management in SME into Practice}

The following chapter deals the simulation of process model of strategic management in SME into practice in the form of case study of the selected building enterprise, marked as enterprise A under the promise of its anonymity. The main reason for selected this enterprise is its willingness to be in detail participated in this project, its previous cooperation of research [13] and possibility on the other cooperation (especially by implementing the proposed model into its business processes). The case study derives from the information of financial statements, annual reports, web sites and personal interviewing with owner-managers of the enterprise A. The enterprise A was established in 1997 such as building joint stock company with basic capital 10 million CZK employing approximately on average 15 employees. It is presented as "a professional and experienced construction enterprise that is engaged in the construction of new apartments and family houses; its services related to the construction and sale of real estates focused on the attractive locations of the Brno region". The subject of the enterprise's activities is the construction of buildings, including their alterations and removals. The aim of all projects is to combine the purpose of the layout solution with an attractive modern design and a high standard of design. As one of the few enterprises on the market, enterprise A offers a purchase of cooperative flats. Part of the enterprise's services consists of legal services to clients or advice on the use of mortgage loans. With quality and modern concepts, enterprise A can satisfy even the most demanding customer. During the construction, it also offers a solution of client changes in the equipment of the apartment according to the customer's requirements.

The main purpose of this case study is to evaluate a quality of implementing the strategic management principles into business processes. First of all, the author forced to find out if the enterprise A implements all of the identified determinants of strategic development in SME and basic pillars of strategic management (analyzing, planning, implementing, controlling). Based on the personal interviewing with ownermanagers it could be stated no comprehensive strategic management principles are in enterprises A implemented. Therefore the process model of strategic management in SME could not be directly implemented into processes of enterprise A. Firstly, the following information describes the current situation in enterprises A. Afterwards, the main strengths and weaknesses of enterprise A have been identified. Finally, the 
missing used determinants of strategic development SME have been complemented and used for process model in enterprise A proposal (see Figure 2).

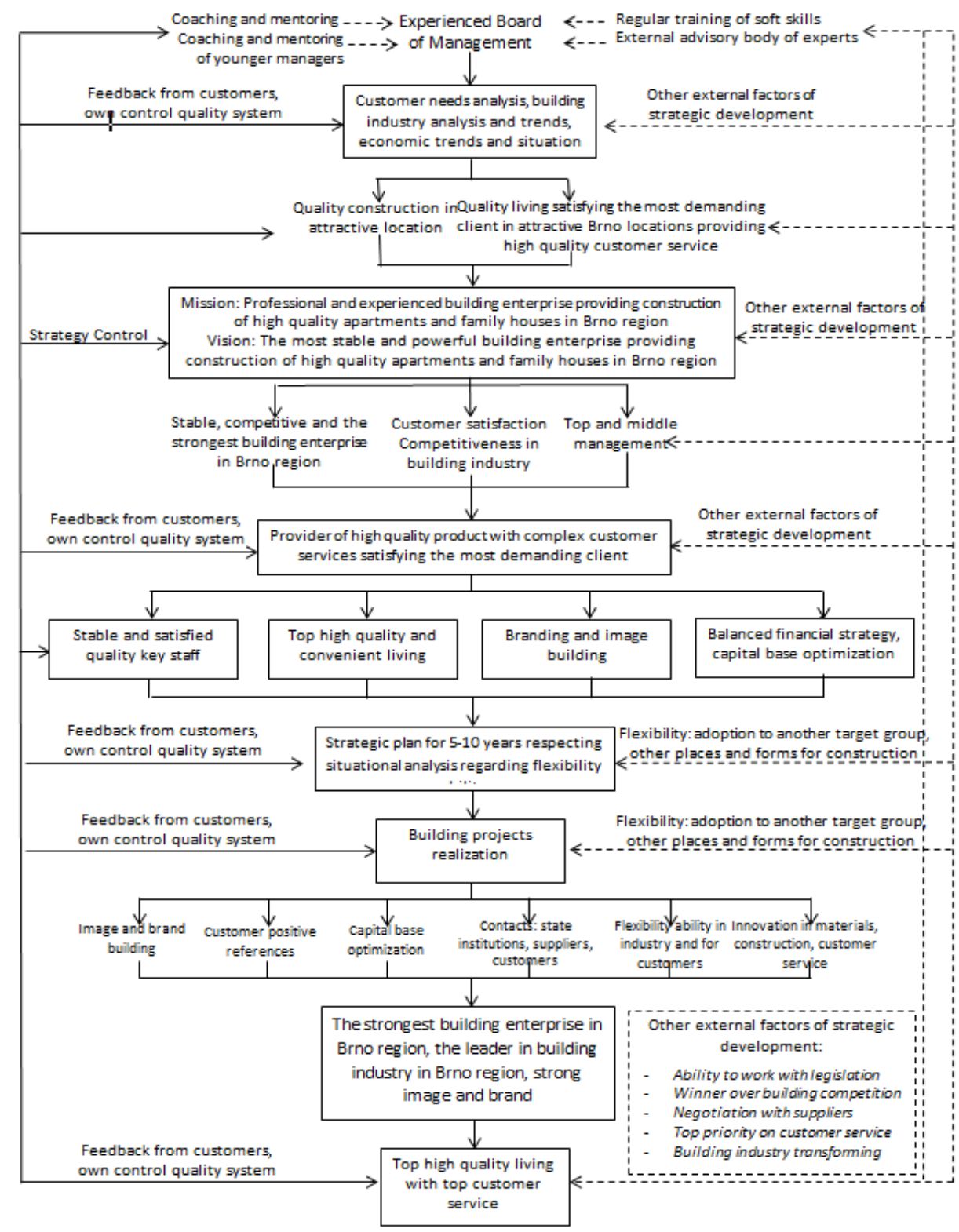

Fig. 2. Process Model of Strategic Management in enterprise A.

This proposed model is served at the series of recommendations for optimizing the whole process of strategic management and implementing its principles in enterprise 
A and at the same time eliminating the main weaknesses that threaten the stability of whole enterprise and the possibility to be developed. This model was subsequently discussed with board of management that decided to implement it into next annual strategic plans.

The process model from Figure 2 describes main determinants of strategic development implemented into current business processes in enterprise A. Simultaneously, this model proposes these determinants that have not been identified and used here yet, i.e. instruments for improving managerial skills, identification of innovative product, proposal of mission and vision, defining the business concept and idea, strategic thinking and key staff, identification of functional strategies, form of strategic control and change management, and long-term goals in the form of outputs of the model. Based on personal interviewing with owner-managers, top management uses some of these principles, indeed mainly based on their experience and intuition. Top management consists of three members of board management that has been managing the enterprise A since its establishment. Their form of managing the enterprise $\mathrm{A}$ is based mainly on intuition and 20 years of experience from the field of building and construction. No previous management experience has been implemented here. The process model recommends to follow modern trends in management with regular trainings of soft managerial skills (they have never done so yet), hiring the external advisory body experts (from the area customer relationship management, personnel management, marketing management, strategy building and implementing). Based on internal analysis, these areas of enterprise A are considered to be the most critical or insufficient. It is also recommended to use regular coaching and mentoring in managerial skills by selected experts that could disclose possible problematic areas in management and help with strengthening the position of enterprise A. After that, it is recommended to start training younger managers such as successors (in the form of coaching and mentoring current top management) from middle management that could undertake the whole top management of enterprise A in the future. Owner-managers are aware of this situation, but they have not started implementing any action. These recommendations require long-term financial and non-financial investment into enterprise A that change the current strategic approach, nevertheless it could enable to develop the enterprise A and to strengthen its current strategic position.

The process model continues with external situational analysis that enterprise A regularly evaluates, especially trends and legislative changes in building industry, economic analysis of the market including regular internal financial analysis is deeply underestimated, therefore it is recommended to imply these analyses into everyday practices realized by internal or external staff. Customer needs analysis is also recommended to be provided for instance in the form of survey of customer satisfaction and needs that is also underestimated. The situational analysis is then used for competitive advantage (based on quality construction and attractive location of construction) and innovative product (based on quality living satisfying the most demanding client in attractive Brno locations providing high quality customer service) identification. When exploring the own opinion of owner-managers on competitive advantage and innovative product, they were hardly thinking of its clear identification 
and especially there is no written document that identifies key components of tis entrepreneurship. These determinants are consequently used for mission and vision definition (their specifications are given in figure 2). Even in this area, enterprise A does not identify them. Mission and vision is then transformed into business concept and idea, identified as stable, competitive and the strongest building enterprise in Brno region, strategic thinking based on customer satisfaction and the strongest competitiveness in building industry and key staff that should be consisted of top management and competencies of middle management (nowadays it is missing here).

The other procedural step of this model is based on corporate strategy definition. Owner-managers declared enterprise A identifies strategy based on quality and orientation on customer. Its clear definition is, however, missing in any written form. The model recommends the following strategy formulation: Provider of high quality product with complex customer services satisfying the most demanding client. It was also detected the no functional strategies are in enterprise A identified and even any extra responsible person or middle-manager is responsible for each identified area. The model attempts to eliminate these shortcomings. Firstly, HR strategy should be based on care of stable and satisfied quality key staff, i.e. to implemented benefit and motivational system attracting the most quailed staff from the field. Production strategy is based on providing top high quality and convenient living that closely relates to overall strategic approach of enterprise A. The marketing area of enterprise A is deeply underestimated and is considered as the same priority as other areas. Therefore, marketing strategy should be oriented on branding and image building in building industry. For implementing this strategy it is needed to hire external or even internal marketing managers that could strongly help the overall strategic management process. This area requires again more significant financial and nonfinancial investments that could be quickly returned back in case of its effective implementation and long-term priority care. The last financial strategy is based on balanced financial approach based on improving liquidity and profitability level and also based on capital base optimization. The last five years were connected with financial losses or low profit and financing mainly by short-term liabilities. Now financial manager is working for enterprise A. It is therefore recommended to hire responsible person for deep financial analysis and audit to optimize these processes.

Based on corporate and functional strategies identification, the strategic plan for next 5-10 years should be set up and further realized in the form of projects with prior orientation on investment strategic approach to strengthen the strategic position with corporate culture based on image and brand building, together with more efficient case for customers and building their loyalty, financial and capital base optimization and implementing principles of change management and to be flexible and to be prepared to adapt to customers and building industry and to build innovation ability in materials, customer service and construction. During the whole process the feedback and control processes are realized with concision of external factors of strategic development mentioned in figure 2 . The out of the whole process is fulfilling the main business goals such as the strategic positon, image and branding, firstly in Brno region then in other territories in case of long-term financial success. Even though, all business goals are reached, the enterprise A is forced to think over permanent 
innovation of product and customer services provided. This process highlights the strengths and eliminates the weaknesses in strategic management process of enterprise A. This model enables to strengthen the strategic position and optimizes the whole observes process; thereby it was verified into practice.

\section{Conclusion}

The main purpose of this paper was to verify and simulate the theoretically proposed strategy process model of strategic management in SME into the practice in form of case study (on an example of selected enterprise A from building industry). Based on the internal analysis and personal interviews with owner-managers of selected enterprise A, it could be stated the forming this model could be applied in practice and this model could be used in other strategic decision-makings. Owner-managers agree with the forming of this model and its practical usage. The main benefits of this model are based on highlighting the most important determinants for strategic development in SME, giving the consequences in strategic management process and reciprocal incidences. At the same time, the model could identify the shortcomings in implementing the strategic management that could threaten strategic plans and reaching main strategic goals of the enterprise. Based on the simulation of strategic process model for the enterprise A, the main benefits and shortcomings in the process of strategic management have been identified and subsequently the recommendations for elimination of identified shortcomings have been proposed. These recommendations have been discussed with owner-managers. They decided to deal them with all members of board of management. This model could be served as an inspiration for optimizing the process in business development from theoretical and practical point of view. The results of the case study cannot be generalized for the whole research sample; nevertheless, it could be served as a basis for other research activities in this field. The research has been provided a detailed internal analysis and information about selected SME that could compare its strategic processes with the current theoretical findings in this field.

Acknowledgements. This paper has been prepared in terms of the project IGA of the Mendel University in Brno titled as "Importance of Strategic Management in Small and Medium-sized Entrepreneurship" with registration number FRRMS - IGA $2017 / 024$.

\section{References}

1. Analoui, F., Karami, A.: Strategic management in Small and Medium Enterprises. 1st edn. Thomson Learning, London (2003).

2. Burke, G. I., Jarratt, D. G.: The Influence of Information and Advice on Competitive Strategy Definition in Small and Medium-sized Enterprises. Qualitative Market Research: An International Journal 7(2), 126-138 (2004). 
3. Carter, S. Jones-Evans, D.: Enterprise and Small Business: Principles, Practice and Policy. 3rd edn. Pearson Education Limited, London (2012).

4. Duygulu, E. at al.: The Sustainable Strategy for Small and Medium Sized Enterprises: The Relationship between Mission Statements and Performance. Sustainability 8 (7), 691-698 (2016), DOI:10.3390/su8070698.

5. Halici, A., Erhan, D. U.: Structuring strategic management with ratio analysis method: a case study in the transition to SME TFRS process. Procedia - Social and Behavioral Sciences 99, 947-955 (2013), DOI: 10.1016/j.sbspro.2013.10.568.

6. Holátová, D. Březinová, M., Kantnerová, L.: Strategic Management of Small and Medium-sized Enterprises. WSAES Transactions on Business Economics 12(7), 65-73 (2015).

7. Karami, A.: Strategy Formulation in Entrepreneurial Firms. 1st edn. Ashgate Publishing, Hampshire (2012).

8. North, K., Varvakis, G.: Competitive Strategies for Small and Medium Enterprises: Increasing Crisis Resilience, Agility and Innovation in Turbulent Times. 1st edn. Springer International Publishing, Switzerland (2016).

9. Šebestová, J., Nowáková, K.: Dynamic strategy for sustainable business development: mania or hazard? The Amfiteatru Economic Journal 15(34), 442-45 (2013).

10. Srpová, J. Řehoř, V.: Základy podnikání: Teoretické poznatky, př́iklady a zkušenosti českých podnikatelů. 1st edn. Grada Publishing, Praha (2010).

11. Stokes, D., Wilson, N.: Small Business Management and Entrepreneurship. 5th edn. Cengage Learning EMEA, UK (2010).

12. Svatošová, V.: Possibilities of Strategic Development in Small and Medium-Sized Entrepreneurship. In: Proceedings of the XI. International Scientific Conference ICABR 2016, Mendelova univerzita, Brno (2016). "in print"

13. Svatošová, V.: Importance of Strategy and Aspects of Strategic Development in Small and Medium-Sized Entrepreneurship. Ekonomický časopis, (2017a). "in print"

14. Svatošová, V.: Simulation of Process Strategy Model in Small and Medium-sized Entrepreneurship. In: Jedlička, P., Marešová, P., Soukal, I. (eds.) Hradec Economic Days 2017, vol. 7(1), pp. 845-862. University of Hradec Králové, Hradec Králové (2017).

15. Svatošová, V., Kašparová, Z.: Modelling the Process of Strategic Management in Small and Medium-sized Entrepreneurship. In: Region v rozvoji společnosti 2017, Mendelova univerzita, Brno (2017). "in print"

16. Zich, K.: Koncepce úspěchuschopnosti a její pojetí strategie. E+M Economics and Management 13(1), 60-73 (2010). 